\title{
Sobre a tradução em Jacques Derrida
}

\author{
Thaís Fernandes dos Santos*
}

\begin{abstract}
Resumo
Busca-se refletir, nesta exposição, acerca das contribuições do pensamento de Jacques Derrida (1930-2004), a herança teórica do autor associada à Filosofia e à Literatura, na tentativa de compreender importantes conceitos, como escritura, ilegibilidade, jogo, perdão e, sobretudo, noções de relevância e de fidelidade em tradução. Parte-se, para tanto, de excertos do livro intitulado Gramatologia (1999) e de artigos e ensaios críticos, dentre eles, O que é uma tradução 'relevante'? (2000), nos quais observa-se as preocupações filosóficas do pensador franco-argelino e a questão da quase intraduzibilidade, como um acontecimento da linguagem humana.

Palavras-chave: Jacques Derrida. Escritura. Literatura. Tradução.
\end{abstract}

\footnotetext{
* Universidade de São Paulo (USP). Estudante do Curso de Mestrado junto ao Departamento de Letras Modernas, da Faculdade de Filosofia, Letras e Ciências Humanas, da Universidade de São Paulo, no Programa em Letras Estrangeiras e Tradução, Área de Concentração: Estudos da Tradução. Bolsista CAPES. ORCID: 0000-0003-0502-5832.
}

Cadernos CESPUC de Pesquisa. Série Ensaios. n.38, 10 Sem./2021, p. 29-45. e-ISSN: 2358-3231 (OJS). Recebido em: 19/06/2021. Aceito em: 27/08/2021. 


\title{
Jacques Derrida on translation
}

\author{
Thaís Fernandes dos Santos
}

\begin{abstract}
This paper reflects on the contributions of Jacques Derrida (1930-2004), related to Philosophy and Literature as an attempt to understand important concepts such as written language, illegibility, game, forgiveness, and mainly, notions of relevance and fidelity in translation. The theoretical framework of this paper includes excerpts from Grammatology (1976 [1999]), and articles and essays, among them What Is a 'Relevant' Translation? ([2001] 2000), in which we will see Derrida's philosophical concerns and issues of almost an untranslatable nature, as an event underlying human language.
\end{abstract}

Keywords: Jacques Derrida. Written language. Literature. Translation. 


\section{Palavras iniciais}

Não creio que nada seja sempre intraduzível — nem traduzível, aliás.

Como podemos ousar dizer que nada é traduzível, tanto quanto nada é intraduzível? A que conceito da tradução é necessário apelar para que esse axioma não seja simplesmente ininteligível e contraditório: "nada é traduzível ou nada é intraduzível"? Na condição de uma certa economia que aproxima o traduzível do intraduzível, não como se aproxima o mesmo do outro, mas o mesmo ao mesmo ou o outro ao outro.

(Derrida, 2000, p. 18-19 [itálico do autor])

Em seu ensaio intitulado Che cosè la poesia? (2001a [1988]), o filósofo franco-argelino Jacques Derrida (1930-2004) chama a atenção para o jogo da significação, a experiência e a mecânica poéticas; a impureza, de certo modo, contidos na natureza da Poesia - "escrita, falada ou mesmo cantada" (DERRIDA, 2001a, p. 113). Nesse caminho de formas de palavras, onde habitam a origem do afeto sincero, do poético, o que ele denomina como o "corpo das letras", ou seja, associado ao que toca o coração, ao que nos ensina o coração, à unicidade do poema, nisso está, também, o encantamento do silêncio da própria poesia, do que seja, talvez, difícil de ser decifrado e, portanto, intraduzível para qualquer língua.

Derrida (2001a [1988]) enfatiza dizendo, nesse sentido, que "quando, ao invés de poesia, dissemos poética, deveríamos ter especificado: poemática" (DERRIDA, 2001a, p. 115, grifos do autor). E, partindo dessa leitura, é interessante observar a questão da (im)possibilidade da tradução de poesia, sobre a qual muitos estudiosos têm se ocupado em anos recentes, por exemplo, no domínio dos Estudos da Tradução, com ênfase em poéticas comparadas, em que se dispõem a um duplo esforço para, talvez, melhor justificar o que, possivelmente, coloca-se como o maior desafio em seu ofício tradutório: preservar a forma ou o conteúdo do poema, aqui entendido como o original.

No entanto, ao que parece, o ensaio Che cosè la poesia? (2001a), em cuja tradução para o português brasileiro optou-se por manter o título mesmo em italiano, sugerindo, assim, a "tradução recíproca", marcando 
os dois sistemas linguísticos, ${ }^{1}$ aproxima-se, na verdade, de uma tentativa de formular perguntas, ou do ato de questionar a partir de algo inerente à própria língua, ao formular indagações como "o que seria o infinito?” ou, afinal, "o que é um romance?", ou, ainda, de tentar responder à questão figurada no título do referido ensaio; então pensado nessa exposição provocativa feita por Derrida.

As suas contribuições filosóficas e literárias, todavia, não ignoram outras maneiras de se pensar as palavras, como o ato de tradução, a sua ressonância ética e, sobretudo, o engajamento que ele pode suscitar no leitor. É também tendo em vista a reflexão sobre a intraduzibilidade, lembra Derrida, em seu livro sob o título de Torres de Babel (2006), da responsabilidade de acolher o Outro, ${ }^{2}$ e considerando as relações entre língua escrita, cultura e sociedade, que nos remetemos às noções de relevância e de fidelidade ao texto, atravessadas no seu pensamento. Haveria de ser, portanto, estes dois últimos conceitos, quais sejam, o de relevância e de fidelidade, a merecerem uma atenção acurada, para se evitar a irredutibilidade da singularidade idiomática, do significado, ou, como observado, daquilo a que esteja relacionado à prática da atividade tradutória.

Do traduzível ao intraduzível, revisitando a epígrafe citada na abertura deste texto, convém relembrar o excerto da conhecida carta escrita por São Jerônimo (395 D.C), endereçada a Pamáquio sobre os problemas da tradução. Nela, São Jerônimo revela o vazio angustiante de quem encontra-se nos limites da interpretação, o seu fazer tradutório, intimidado pela rigidez da economia das palavras, sob a inquietante questão de como "deveria" ser a tradução (a tradução de uma letra morta?). ${ }^{3}$ Angústia originada no fato de que ele próprio, tradutor, haveria de ser (in)fiel ao manuscrito da língua original, a língua de erudição, onde então jazia um pensamento escolástico, na Europa Ocidental.

\footnotetext{
1 Referimo-nos à expressão "tradução recíproca" em consonância com os estudos do pesquisador Paulo Ottoni (2000, p. 131) sobre o conceito de double bind, que, segundo o autor, ele consiste na "possibilidade e a impossibilidade - a necessidade e a impossibilidade - da realização deste acontecimento".

$2 \mathrm{O}$ conceito de hospitalidade, em Jacques Derrida, está associado às noções de cultura, de estrangeiro e ao gesto ético como acolhimento, de aceitação incondicional do outro, remetendo-se inclusive à uma dimensão política das nações na contemporaneidade.

3 Friedrich Daniel Ernst Schleiermacher, ao discorrer sobre a tradução em seu conhecido ensaio intitulado Sobre os diferentes métodos de traduzir (2010 [1813], p. 41), acentuou que a "prática [da tradução] não é usada apenas para transplantar em solo estrangeiro o que uma língua produziu no domínio da ciência e das artes discursivas, e assim aumentando o círculo de atuação destes produtos do espírito, mas também esta prática é usada no comércio entre diferentes povos e nas relações diplomáticas de governos independentes entre si, quando estes apenas podem falar com o outro em sua própria língua, se eles, sem servirem-se de uma língua morta, querem manter-se rigorosamente em uma igualdade". Também Antoine Berman (2007, p. 31) acrescenta que a prática da tradução, particularmente na cultura romana, "[...] não se importa com a letra morta: ela vai, para captá-lo, até ao espírito, ao sentido. Enquanto a tradição judaica desconfiava da tradução, é realmente um imperativo categórico do cristianismo a tradução do Livro em todas as línguas, a fim de que o sopro vivificante do Espírito atinja todas as nações (Atos dos Apóstolos, 2, 4)”.
} 
Essa problemática, desde a crise da escolha lexical ao literalismo, no sentido de palavra por palavra, remete-nos às clássicas discussões teóricas e ideológicas incluindo a confusão babélica, de que discorreu, com propriedade, o crítico literário George Steiner (1975), em torno da suposta exatidão - conteúdo versus estilo - , ou da noção de fidelidade, na história da tradução. Problemática também desenvolvida no artigo intitulado $O$ que é uma tradução 'relevante'? (2000), de Jacques Derrida, com respeito à peça teatral de William Shakespeare (2006 [1986]), ambientada na cidade de Veneza, Itália, do século XVI, sobre o qual trataremos brevemente mais adiante.

\section{Da relação entre a escrita e a Literatura}

Nunca se escreve nem na própria língua, nem numa língua estrangeira.

(Derrida, Sobreviver, 1986 [2005], p. 21) ${ }^{4}$

Em seu artigo "Jacques Derrida, o intraduzível”, o escritor Marcos Siscar (2000) observa que a "temível e irredutível dificuldade da tradução é aquilo que inaugura o conhecimento, a verdade do conhecimento da tradução como tradução" (SISCAR, 2000, p. 61). A essa observação, acrescentaríamos que a tradução é um processo de crítica, que nos conduz a pensar que ela é uma modalidade de leitura sobre a configuração efetiva de um discurso, seja esse discurso científico, filosófico, seja literário, teológico.

Reconhece-se que tentar aqui, nesta breve exposição, uma possível definição que aproxime os diversos conceitos propostos por Derrida é um caminho desafiador. O que se propõe a discutir e a estudar com atenção em seus escritos científico-filosóficos e, também, no domínio dos Estudos literários, mais particularmente, nos eixos da crítica comparada e da tradução escrita, é a seguinte questão: "quem ou o que é comparado?", proposta em seu ensaio seminal intitulado Who or What Is Compared? The Concept of Comparative Literature and the Theoretical Problems of Translation (2008).

Pensando, nesse sentido, no espectro da escrita literária, especificamente ao que segue ao tom provocativo do referido enunciado

4 Epígrafe colhida do ensaio intitulado "Carta a um amigo japonês" (2005), de Derrida. 
discursivo, que constitui a pergunta: "quem ou o que é comparado?" feita por Derrida, é interessante lembrar o que salientou Jonathan Culler. O crítico e professor americano, em seu artigo The Most Interesting Thing in the World (2008), destaca, nos eventos literários, a estrutura narrativa ficcional que lhes confere expressividade dando um significado político à literatura, tal como o gesto democratizante, ligado, por sua vez, a um assunto literário em prosa.

Nesse ponto, Jonathan Culler, um dos responsáveis por introduzir o pensamento de Derrida nos países de fala inglesa, em especial nos Estados Unidos e na Inglaterra, argumenta sobre literatura e democracia, em seu artigo já aludido, ressaltando o que diz Derrida sobre a Literatura. De acordo com Culler, Derrida considera que "ela [a literatura] pode ser 'a coisa mais interessante do mundo... mais interessante do que o mundo', porque ela ultrapassa o real, também inclui suas possibilidades expondo sua condição de possibilidade" (CULLER, 2008, p. 9, tradução nossa [grifo do original]). ${ }^{5}$

Assim, Derrida dirá, mais adiante, em seus escritos, a exemplo da entrevista datada de 1989, atendendo ao convite do acadêmico britânico Derek Attridge, intitulada Essa estranha instituição chamada literatura (2014), que, com respeito à natureza da literatura e da crítica literária, há questões éticas nelas contidas. Observações semelhantes a estas, com respeito à literatura e ética, foram também feitas pelo pesquisador Marcos Natali, ao discorrer mais especificamente sobre passagens da obra Circonfissão (2013 [1996]), de Derrida, acentuando que "o interesse [de Derrida] pela literatura virá de sua capacidade para dramatizar características encontradas também em outros discursos, além de seu poder de formular perguntas difíceis à filosofia" (NATALI, 2013, n.p.).

Ao que parece, é nessa chave de leitura que Derrida procura, talvez, realçar a sua escritura em Língua Francesa, ou, como ele sugere, em entrevista já mencionada, que toda experiência pode ser uma leitura literária, no sentido que, para ele, "toda linguagem se refere a algo além de si mesma ou à linguagem como alguma outra coisa. Não se deve escamotear essa dificuldade" (DERRIDA, 2014, p. 70). E, nessa linha argumentativa, sugerindo a ideia de teorização do texto,7 e preocupando-se com a questão da língua, ele formula a seguinte pergunta: "será que sua originalidade consiste

\footnotetext{
5 No texto original em Inglês: Literature can be "the most interesting thing in the world... more interesting than the world" because it exceeds the actual but includes its possibilities, opening their condition of possibility.
} 
em parar e prestar atenção nesse excesso da linguagem sobre a linguagem?" (DERRIDA, 2014, p. 70). É indagável, diante desta questão formulada, se estaria ele falando a partir da Linguística ou da Crítica literária.

Partindo dessas reflexões propostas como pano de fundo, e pensando nesses temas que aqui se aproximam, a literatura e a tradução ou, o que é intraduzível e a Literatura comparada, ambas funcionando como práticas discursivas, que resultam das interações humanas, culturais e sociais da contemporaneidade, o filósofo franco-argelino propôs o seguinte questionamento: "pode um nome próprio ser traduzido? E o que devemos fazer com os nomes próprios na tradução literária?” (DERRIDA, 2008, p. 35).

Naquele primeiro momento, a resposta que ele deu, sem demora, à essas perguntas é que os nomes próprios não podem ser traduzidos e, em seguida, esclareceu que no tecido dos signos linguísticos, "às vezes eles [os nomes próprios] são adaptados a nível da pronúncia ou da transcrição fonética, como os nomes de cidades: Londres, London, Venezia, Veneza, Venise; e Londres não é uma tradução de London" (DERRIDA, 2008, p. 36 , grifos nossos), ${ }^{6}$ e, por isso mesmo, eles não poderiam ser traduzidos. Portanto, estamos diante de um caso que exemplifica a intraduzibilidade, conforme Derrida.

Observa-se, nessa perspectiva, que, assim como os supostos sintagmas idiomáticos das línguas alemã, francesa e inglesa são um problema de tradução, assevera Derrida, as palavras acima mencionadas, "Londres, London, Venezia, Veneza, Venise", são também "consideradas intraduzíveis porque não têm significado; não têm um significado conceitual e comum; elas são somente um referente, quer dizer, um referente único" (DERRIDA, 2008, p. 36-37). ${ }^{7}$ Isso significa dizer que, enquanto tal, o nome próprio não pertence ao "sistema da língua", sugere Derrida, no sentido de que não é possível realizar qualquer translação semântica. Como resultado, essas questões de linguagem, associadas ao material lexical, aparentemente paradoxais, apresentam uma resistência contínua à tradução, que traz consigo regiões inteiras de intraduzibilidade linguística.

\footnotetext{
6 No texto original em Inglês: They are sometimes adapted, in pronunciation or transcription (like the proper names of cities: Londres, London, Venezia, Venice, Venise; but Londres is not a translation of London, but they cannot be translated.

7 No texto original em Inglês: They are taken to be untranslatable because they have no meaning, no conceptualizable and common meaning; they only have a referent, as one says, a unique referent.
} 
Ao retomarmos, portanto, a leitura da epígrafe reproduzida nesta seção, veremos a problemática em torno da palavra, a leitura da palavra outra, estrangeira, no pensamento do filósofo; e sendo assim, a linguagem um dos temas relevantes na escritura de Derrida, bem como uma forma de ele questionar a tradição ético-política. (DERRIDA, 2014). Ainda nesta reflexão, o nosso gesto de interpretação da sua escrita busca revisitar, a partir de leitura de seus textos mais extensos, referenciados na bibliografia, a contribuição do pensador para o que, aqui, entendemos por "movimentos da linguagem".

Esses movimentos dos valores de um signo sob o nome de linguagem, como esclarece adiante Derrida, referem-se aos movimentos das ciências, da natureza, da alma, por sua vez, inspirada no logos em grego $\lambda o ́$ os, equivalente em português ao discurso, à lógica, à razão, portanto, capazes de, nessa linha, revelar a "comunicação, relação, expressão, significação, constituição do sentido ou do pensamento etc." (DERRIDA, 1999, p. 08), na tentativa de dar sentido à experiência humana. E é nessa direção, em seu discurso metafísico ocidental, inclusive com respeito aos trabalhos do também filósofo Jean-Jacques Rousseau (1712-1778) e ainda do antropólogo Claude Lévi-Strauss (1908-2009), que Derrida problematiza a noção de escritura versus fala, ao propor o neologismo "falogocentrismo", na obra intitulada Gramatologia (1999).

Nessa obra, a crítica de Derrida ao estruturalismo linguístico, centrado no signo e no seu aspecto arbitrário, formulado pelo genebrino Ferdinand de Saussure (1857-1913), retoma o problema da identidade, a noção de linguagem como "escritura," cujo conceito não implica necessariamente o sentido de que a "escritura" está associada à mera produção de um texto escrito. Para Jacques Derrida, a palavra escritura possui um valor "pensante" e o "advento da escritura é o advento do jogo" (DERRIDA, 1999, p. 08). Ou seja, o jogo entre as palavras, a indecibilidade. Derrida enfatiza, nessa linha crítica, que existe uma tendência "a designar por 'escritura' não apenas os gestos físicos da inscrição literal, pictográfica ou ideográfica, mas também a totalidade do que a possibilita; e a seguir; além da face significante, até mesmo a face significada" (1999, p. 11, grifo do autor). Logo, parece-nos, a noção que se cultiva a respeito da escritura está associada ao "complemento da fala", "da voz e do sentido de ser" (DERRIDA, 1999, p. 14). 
A referida escritura, também chamada de "arquiescritura", diz respeito "à inscrição geral do traço, como forma de comunicação em que não há mais oposição simples entre significante e significado, forma e conteúdo, corpo e espírito, matéria e transcendência etc." (DERRIDA, 2014, p. 16). Nessa mesma reflexão, Derrida argumenta insistindo que "a 'ciência' semiológica ou, mais estritamente, a linguística, não pode conservar a diferença entre significante e significado, a ideia de signo, sem a diferença entre o sensível e o inteligível" (DERRIDA, 1999, p. 16, grifo do autor). Pois, segundo ele, os conceitos atribuídos à linguagem natural parecem estar relacionados sobretudo a um principal modelo linguístico em particular, o estruturalismo. Desse discurso explicativo, Derrida coloca, mais adiante, em questão a consciência da unidade lexical "palavra": "e todos os privilégios que lhe são, em geral, reconhecidos, sobretudo sob sua forma nominal" (DERRIDA, 2005, p. 26, grifo do autor).

Interessantemente, esse conjunto de conceitos-chave, por assim dizer, nos domínios da Linguística, ou, preferível, da história da Semiótica, enquanto "ciência positivista" (DERRIDA, 1999, p. 91), que aponta a oposição entre fala-escrita, a conhecida crítica à metafísica logocêntrica sobre o privilégio da palavra falada, palavra escrita; entretanto, sensívelinteligível; significante-significado e assim por diante. Isso, ao que parece, aqui, depender da definição de outros conceitos ou, ainda, que tais noções fariam o trabalho de mediação entre os demais conceitos formulados pelo próprio Jacques Derrida, dentre eles, "arquiorigem, différance, jogo, presença, signo, simulacro” (SPIVAK, 1976, p. ix), ao passo que estes últimos seriam derivados de um sistema de pensamento, isto é, a desconstrução discursiva, como uma possibilidade de leitura crítica.

\section{Da tensão entre o intraduzível e a tradução}

Não falei de intraduzibilidade ou de idiomaticidade absolutas, mas de uma maior economia (tratava-se para mim de dizer em poucas palavras francesas, neste caso, nessa ocorrência, o que se pode traduzir, de todo jeito, em toda língua, com menos gastos); o que basta para mudar o sentido político deste gesto.

(Derrida, 2001, p. 106 [itálico do autor]) 
Considerando a atividade da desconstrução, ou seja, do fato de que os termos e os conceitos em tradução desafiam a Filosofia, Derrida destacou, em Gramatologia (1999), as produtivas discussões teóricas que colocam a escrita por objeto. Convém destacar o trabalho intitulado On deconstruction: theory and criticism after structuralism (1982), de Culler, em capítulo que discorreu sobre a Escrita e Logocentrismo, por exemplo.

A Desconstrução, nesse sentido, foi também discutida pela tradutora americana Barbara Ellen Johnson (1981), que a partir da leitura particular da obra Dissemination (1972), de Derrida, buscou ressaltar o sentido da palavra desconstrução, que, conforme argumenta a escritora-tradutora, "não está relacionado à palavra 'destruição', mas sim à palavra 'análise', que, etimologicamente, significa 'desfazer', algo semelhante a 'desconstruir"' (JOHNSON, 1981, p. xiv, tradução nossa, grifos da autora). ${ }^{8}$

Essa observação feita por Barbara Johnson, em defesa do que significa, afinal, a palavra "desconstrução" no pensamento de Derrida, demonstra a importância dada à essa questão, especialmente nos círculos anglo-americanos, uma vez que a Desconstrução é também uma estratégia de escrita, senão uma tradução onde tudo é leitura - há intervenção do sujeito - , na medida em que se concentra nos fundamentos de um sistema de pensamento, no cenário pós-moderno. Assim, a Desconstrução, se constitui como uma das vertentes dos Estudos da Tradução; e, nesse sentido, Derrida, em seu ensaio "Carta a um amigo japonês" (2005), ocupase em responder, ou tentar responder, à (im)possível tradução da palavra desconstrução para a Língua Japonesa. Nesta breve carta, endereçada ao seu amigo filósofo e professor Toshihiko Izutsu (1914-1993), Derrida então sublinha dizendo que a "desconstrução não é nem uma análise nem uma crítica, e a tradução deveria levar isso em conta" (DERRIDA, 2005, p. 24, grifos do autor).

Nessa reflexão, é verdade que Derrida não intentou dar uma resposta determinada ao que é ou não deveria ser a desconstrução, ao contrário, nessa mesma observação, ele parece desdobrar a sua argumentação colocando, uma vez mais, a questão da dificuldade de definir tanto a palavra "desconstrução" como a palavra "tradução". A esse propósito, lembra Lenita Esteves (2014), em sua pesquisa sobre Tradução e Ética, “Derrida dá um

\footnotetext{
8 No texto original em Inglês: "In fact, the word "de-construction" is closely related not to the word 'destruction' but to the word 'analysis', which etymologically means 'to undo' - a virtual synonym for 'to de-construct.".
} 
tratamento filosófico à tradução em vários de seus textos, reiterando alguns pontos fundamentais" (ESTEVES, 2014, p. 153), e, mais adiante, destaca a pesquisadora, "talvez o mais conhecido deles seja a ideia de um dilema insolúvel: a tradução é, ao mesmo tempo, necessária e impossível” (ESTEVES, 2014, p. 153).

Entendemos, nesse sentido, em Derrida, uma complexa articulação em relação à profusão de conceitos presentes nos seus volumosos estudos, como "diferença, escritura, ilegibilidade e relevância", bem como a noção de "intraduzibilidade". No que é relativo à materialidade formal da obra que a tornaria intraduzível, esses conceitos remetem-nos ao que ele chama de acontecimentos na linguagem humana, repousados sobre a tendência de interromper o que é possível, e o que é dizível, do pensamento. Ou seja, próprio revela: "enquanto pensamento do impossível, a desconstrução acaba por tornar-se uma afirmação performativa” (DERRIDA, 2012, p. 231).

Não por acaso, sob esse âmbito, e ainda no que diz respeito, mais particularmente, à instituição e à tradução da noção de literatura comparada, em seu ensaio Who or What Is Compared? The Concept of Comparative Literature and the Theoretical Problems of Translation (2008), Derrida questiona: "quem contestaria que sem as línguas, os atos e os acontecimentos na linguagem, nenhuma instituição, literatura e tradução teria a menor chance de aparecer ou mesmo de ser imaginada?" (DERRIDA, 2008, p. 25). ${ }^{9}$

Edwin Gentzler (2009), professor de Literatura comparada e estudioso da tradução, em seu capítulo intitulado "Desconstrução", acrescenta a esse pensamento do filósofo que "o interesse de Derrida em tradução é pelo processo antes da denominação, enquanto o 'objeto' ainda não é” (GENTZLER, 2009 [1993], p. 205, grifo do autor). Isso porque, explica o autor, o "processo de tradução descontrói textos e retorna ao ponto antes de um objeto ser nomeado, tornando visível um caminho pelo qual o significado foi redirecionado ou desviado" (GENTZLER, 2009, p. 185-186). ${ }^{10}$ Ademais, em termos de contribuição para Teoria da tradução, percebe-se que a noção de "diferença", ou, ainda, de tradução

\footnotetext{
9 No texto original em Inglês: Who would contest that without languages, acts and events of language, no institution, no literature, no translation could have the least chance of appearing or of even being imagined?

10 Dessa reflexão, Gentzler (2009, p. 185-186, grifos do autor) acentua dizendo que, “Derrida, de fato, 'baseia' sua 'teoria' de desconstrução ou não identidade, ou não presença na não representatividade. O que existe, segundo Derrida, são diferentes correntes de significação — incluindo o 'original' e suas traduções em uma relação de simbiose - suplementando-se mutuamente, definindo e redefinindo uma fantasmagoria de igualdade, que nunca existiu nem jamais existirá como algo fixo, compreensível, conhecido ou entendido. Essa fantasmagoria, produzida por um desejo de alguma essência ou
} 
por "transformação", sugere que o texto traduzido, quer em prosa, quer em poesia, é, para Derrida, um produto autônomo no sistema cultural receptor. É sob esse aspecto que convém relembrar o discurso de Derrida acerca do que é uma tradução relevante, ao tratar da comédia do dramaturgo inglês William Shakespeare quando ele toma como pontos de partida a ideia de tradução ela mesma e a de perdão (em sua natureza de "impossibilidade", do que ele próprio qualifica como "intraduzível”). Entendida, então, como impossível, apesar de não se falar de uma "intraduzibilidade absoluta", como adverte a epígrafe colhida do livro Mal de Arquivo (2001), de Derrida, e citada nesta seção, a tradução é, enfatiza o filósofo franco-argelino, a escritura de um novo texto, em que se observa a diferença entre os sistemas linguísticos, dada a riqueza da língua. Compartilha dessa reflexão André Lefevere (1992), professor e teórico belga, para quem a tradução é, também, uma forma de "reescritura" e, assinala o autor, "qualquer que seja sua intenção, reflete uma certa ideologia e poética” (LEFEVERE, 1992, p. 10), por sua vez, associada ao projeto (editorial ou não) do tradutor e, portanto, ao prestígio que a obra traduzida pode ocupar em um determinado cenário sociocultural.

Nesse sentido, Derrida toma como pano de fundo de suas reflexões a peça teatral O mercador de Veneza (2006 [1986]), vista como um palco da crise ético-religiosa, cujas cenas são marcadas por uma concepção antissemita, na qual a história é encenada colocando em discórdia dois religiosos: de um lado, o mercador Antônio, um cristão; do outro, o agiota Shylock, um judeu, e a dinâmica da narrativa gira em torno de uma promessa, um juramento, uma dívida que o mercador, Antônio, deveria então pagar com uma libra de sua própria carne, como a única forma de pagamento ao agiota Shylock.

Ao tomar como exemplo a cena do endividamento, na peça shakespeariana, Derrida argumenta que, no plano encenado, o "dinheiro" e a "libra de carne" são intraduzíveis, pois trata-se de uma "tarefa possível/ impossível imposta ao tradutor" (DERRIDA, 2000, p. 14), já que "um discurso relevante sobre tradução seria um discurso sobre o perdão, sobre os benefícios da graça que abençoa tanto o que concede quanto o que

unidade, reprime a possibilidade de haver sempre alguma coisa em movimento, em fluxo, 'em ação', fugidia no próprio processo de tentar se definir, falar de si ou se fazer presente". 
recebe. O perdão releva a justiça, diz Portia" (DERRIDA, 2000, p. 13, grifo do autor).

A questão do intraduzível como uma verdade é também observada por Antoine Berman (2007), crítico e teórico francês, que, ao concordar com Derrida, acentua dizendo que "a intraduzibilidade é tendencialmente vivida como um valor. Exalta-se também a traduzibilidade como um indício de alta racionalidade. [...] A intraduzibilidade é um dos modos de autoafirmação de um texto" (BERMAN, 2007, p. 40, itálico do autor). No entanto, Derrida, em "O que é uma tradução 'relevante?" (2000), chama a atenção para o jogo de forças literárias, as perdas e ganhos inerentes ao ofício tradutório, partindo da própria experiência enquanto tradutor para as Línguas Alemã e Inglesa.

Ele argumenta que "uma tradução relevante seria, portanto, simplesmente, uma 'boa' tradução, uma tradução que faz tudo o que dela se espera, uma versão, em suma, que cumpre sua missão, honra sua dívida e faz seu trabalho ou seu dever" (DERRIDA, 2000, p. 17, grifo do autor). E, mais adiante, ele segue esclarecendo que a "relevância" é o que se continua “inscrevendo na língua de chegada o equivalente mais 'relevant' de um original, a linguagem a mais precisa, apropriada, pertinente, adequada, oportuna, penetrante, unívoca, idiomática etc." (DERRIDA, 2000, p. 17, grifo do autor).

E é justamente desse movimento tradutório que resulta o gesto econômico das palavras, de que se refere o filósofo, reproduzidas na epígrafe desta seção. Em sua leitura de $O$ mercador de Veneza (2006), Derrida, no entanto, acentua que a "fidelidade" é a "própria essência e a vocação do juramento: quando eu juro, juro, numa língua, que não há poder, em nenhuma língua humana, de me fazer abjurar, de me desacreditar, quer dizer, de me fazer perjurar" (DERRIDA, 2000, p. 27). Nessa perspectiva, ele pontua dizendo que o "juramento passa pela língua, mas ultrapassa a língua humana - e aí está a verdade da tradução (...) toda a filosofia tem como centro de interesse a noção de tradução" (DERRIDA, 2000, p. 27, grifo do autor). Portanto, em linhas gerais, e como reconhece Gentzler, "ele [Derrida] desafia o leitor (e principalmente o tradutor) a pensar e repensar cada momento em que uma solução de tradução é apresentada, um item dominado, uma identidade fixada ou uma oração escrita" (GENTZLER, 2009, p. 185). 


\section{Palavras finais}

Ao longo desta breve exposição, buscou-se refletir acerca de algumas contribuições do pensamento de Jacques Derrida, na tentativa de compreender relevantes conceitos, passando pelas noções de escritura, ilegibilidade, jogo, perdão e, sobretudo, de relevância e de fidelidade em tradução, respaldados pelas obras que aqui guiaram as nossas leituras. E, como vimos, essas noções, que atravessaram o pensamento do filósofo, trazem consigo muitas outras questões discutíveis, principalmente em torno das leituras críticas a respeito da desconstrução, que pode nos levar a uma postura mais reflexiva a respeito do ato ético, dos assuntos políticos, da escuta de si e a do Outro.

Edwin Gentzler, nesse sentido, observa que o texto de Derrida "nunca é desprovido de um senso de amor pela vida, pela língua e pelo jogo da língua. Afirmando a vida, seus escritos são quase religiosos" (GENTZLER, 2009, p. 204). E é a partir da denominada escritura em Derrida que haveria muito a dizer sobre a tradução em seu pensamento, partindo das obras maiores aqui referidas, por exemplo, e dos estudos acerca da "origem da escritura, a origem da linguagem, as duas questões [que] dificilmente se separam" (DERRIDA, 1999, p. 35), que implicariam retomar a muitos de seus posicionamentos em relação às concepções de linguagem, ou à desconstrução nela intrínseca.

Ademais, sendo ele próprio influenciado pelos trabalhos de Sigmund Freud (1856-1939), faz-se notar, vista a bibliografia aqui consultada, as noções de inconsciente como escrita, de sujeito, identidade, língua e letra, destacadamente, observado em Mal de Arquivo (2001), na investigação psicanalítica do Filósofo. Também Derrida em seus escritos, a respeito dos fenômenos linguísticos em todo seu potencial crítico, questiona a linguística estrutural proposta por Ferdinand de Saussure, em 1970, a separação entre idioma e idioleto, ou língua e fala, além da evidente historicidade, ou seja, da reflexão acerca da ciência da escrita suscitada em Gramatologia (1999).

Podemos, em linhas conclusivas, dizer que a propósito da escritura derridiana, aqui compreendida como um ato, ação, memória narrada, uma marca que sobrevive ao sujeito, capaz de atravessar cenários, que é fundamental compreender o que Derrida desenvolveu sobre o traduzir, 
particularmente o que ele diz sobre assumir para si responsabilidades no processo tradutório, entendido por ele como duplamente relacionado à filosofia, uma vez que a língua influencia o pensamento e, assim, ele a coloca em funcionamento em sua compreensão e trabalho de tradução.

\section{Referências}

BARTHES, Roland. Da obra ao texto. In: BARTHES, Roland. O rumor da língua. Tradução de Mário Laranjeira. $3^{\mathrm{a}}$ edição. São Paulo: Martins Fontes, 2012, p. 70-85.

BERMAN, Antoine. Tradução etnocêntrica e tradução hipertextual. In: BERMAN, Antoine. A tradução e a letra, ou, $\mathbf{O}$ albergue do longínquo. Tradução de Marie-Hélène Catherine Torres, Mauri Furlan, Andréia Guerini. Rio de Janeiro: 7Letras/PGET, 2007, p. 28-43.

CULLER, Jonathan. Writing and Logocentrism. In: CULLER, Jonathan. On deconstruction: theory and criticism after structuralism. Cornell University, 1982, p. 89-110.

CULLER, Jonathan. The Most Interesting Thing in the World. Diacritics, Johns Hopkins University Press, volume 38, numbers 1-2, Spring-Summer, p. 7-16, 2008.

DERRIDA, Jacques. Gramatologia. Tradução de Miriam Chnaiderman e Renato Janine Ribeiro. São Paulo: Perspectiva, 1999, p. 3-208.

DERRIDA, Jacques. O que é uma tradução 'relevante'? Tradução de Olívia Augusta Niemeyer dos Santos. Alfa: Revista de Linguística, UNESP, São José do Rio Preto, São Paulo, v. 44, 2000, p. 13-44.

DERRIDA, Jacques. Che cosè la poesia? Tradução de Tatiana Rios e Marcos Siscar. In: Inimigo Rumor: Revista de Poesia, Rio de Janeiro, n. 10, p. 113116, 2001a [1988].

DERRIDA, Jacques. O monolinguismo do outro ou a prótese de origem. Tradução de Fernanda Bernardo. Porto: Campo das Letras, 2001b, p. 42-65. 
DERRIDA, Jacques. Mal de Arquivo: Uma Impressão freudiana. Tradução de Cláudia de Moraes Rego. Rio de Janeiro: Relume-Dumará, 2001c, p. 8-107.

DERRIDA, Jacques. Carta a um amigo japonês. In: OTTONI, Paulo (org.). Tradução: a prática da diferença. Campinas: Editora da UNICAMP, 2005, p. 21-27.

DERRIDA, Jacques. Torres de Babel. Tradução de Junia Barreto. Belo Horizonte: UFMG, 2006, p. 7-61.

DERRIDA, Jacques. Who or What Is Compared? The Concept of Comparative Literature and the Theoretical Problems of Translation. Translated by Eric Prenowitz. Discourse, Michigan Wayne State University Press, Volume 30, Numbers 1-2, Winter-Spring, p. 22-53, 2008.

DERRIDA, Jacques. Uma certa possibilidade impossível de dizer o acontecimento. Tradução de Piero Eyben. In: Revista Cerrados, v. 21, n. 33, Brasília, 2012, p. 231-251.

DERRIDA, Jacques. Essa estranha instituição chamada literatura: Uma entrevista com Jacques Derrida. Tradução de Marileide Dias Esqueda. Belo Horizonte: Editora UFMG, 2014, p. 7-118.

ESTEVES, Lenita Maria Rimoli. Jacques Derrida: tradução, necessidade e impossibilidade. In: Atos de tradução: éticas, intervenções, mediações. São Paulo: Humanitas/FAPESP, 2014, p. 151-172.

GENTZLER, Edwin. Desconstrução. In: Teorias contemporâneas da tradução. Tradução de Marcos Malvezzi. São Paulo: Madras, 2009, p. 183217.

JOHNSON, Barbara. Translator's Introduction. In: Dissemination (DERRIDA, Jacques, 1972). Illinois: The University of Chicago Press, 1981, p. vii-xxii.

LEFEVERE, André. Prewrite. In: Translation, Rewriting and the Manipulation of Literary Fame. London: Routledge. 1992. p. 1-10. 
NATALI, Marcos Piason. O sacrifício da literatura. Revista Alea: Estudos Neolatinos (Impresso), UFRJ, Rio de Janeiro, v. 15, 2013, p. 201-217.

OTTONI, Paulo Roberto. Tradução Manifesta de double bind: a escritura de Jacques Derrida e suas traduções. Tradterm, São Paulo, v. IV, p. 131, 2000 .

SCHLEIERMACHER, Friedrich Daniel Ernst. Sobre os diferentes métodos de traduzir. In: HEIDERMANN, Werner. Clássicos da teoria da tradução. Tradução de Celso Reni Braida. 2. edição. Florianópolis: UFSC/Núcleo de Pesquisas em Literatura e Tradução, volume 1, 2010 [1813], p. 39-104.

SHAKESPEARE, William. The Merchant of Venice. Fully annotated, with an introduction, by Burton Raffel; with an essay by Harold Bloom. New Haven and London: Yale University Press, 2006 [1986], p. xxxiii.

SISCAR, Marcos Antonio. Jacques Derrida, o intraduzível. Alfa: Revista de Linguística, UNESP, São José do Rio Preto, São Paulo, volume 44, p. 59-69, 2000 .

SPIVAK, Gayatri Chakravorty. Translator's Preface of Grammatology. In: DERRIDA, Jacques: Grammatology. Baltimore: The Johns Hopkins University Press, 1976, p. ix-lxxxix.

STEINER, George. After Babel: Aspects of language and translation. Oxford/England: Oxford University Press, 1975, p. 205- 267. 